\title{
Thermodynamic Analysis of Small Scale Organic Rankine Cycle (ORC) System Based on Dry, Wet and Dry/Wet (Hybrid) Cooling Towers Under Six Climatic Zones of India
}

\author{
Saurabh Pathak ${ }^{1,2}$ and SK Shukla ${ }^{1,2 *}$ \\ ${ }^{1}$ Center for Energy, Resources and Development (CERD), India \\ ${ }^{2}$ Mechanical Engineering Department, Indian Institute of Technology (BHU), \\ Varanasi, India \\ *Corresponding Author: SK Shukla, Center for Energy, Resources and Development \\ (CERD) and Mechanical Engineering Department, Indian Institute of Technology \\ (BHU), Varanasi, India.
}

Received: September 16, 2021

Published: November 25, 2021

C All rights are reserved by Saurabh Pathak and SK Shukla.

\begin{abstract}
This paper presents the thermodynamic analysis of small scale Organic Rankine Cycle under six climatic zones of India namely hot and dry (Jodhpur), hot and humid (Mumbai), moderate (Bangalore), composite (Varanasi), cold and cloudy (Srinagar) and cold and sunny (Leh). The Dry, Wet, and Dry/Wet (Hybrid) cooling towers were selected to predict the power output and thermal efficiency of ORC system. A mathematical model was developed in Engineering Equation Solver (EES) environment to analyze the effect of monthly averaged temperature $\left(\mathrm{T}_{\mathrm{amb}}\right)$ and Relative humidity $(\mathrm{RH})$ on the expander power and thermal efficiency of the ORC system. The expander output of the Organic Rankine cycle (ORC) was $3 \mathrm{~kW}$ and the source temperature was fixed at 100 Numerical investigation finds that with the increase in ambient temperature $\left(\mathrm{T}_{\text {amb }}\right.$ ) and relative humidity $(\mathrm{RH})$, the expander power and thermal efficiency of the ORC cycle degrades. Results show that the ORC performance was observed maximum in the cold and sunny zone (Leh). For the RH variation the maximum expander power output and efficiency were $3.722 \mathrm{~kW}$ and $9.40 \%$ with wet cooling tower. Also, with ambient temperature variation the maximum expander power output and efficiency was $3.83 \mathrm{~kW}$ and $9.683 \%$ with dry mode. The lowest performance of ORC was in the hot and dry zone (Jodhpur). The maximum expander power and efficiency were $2.775 \mathrm{~kW}$ and $6.909 \%$ with wet mode for the ambient temperature variation. Further the maximum power and efficiency was $2.805 \mathrm{~kW}$ and $6.98 \%$ with the wet cooling mode as relative humidity varies. The power output and thermal efficiency varies drastically throughout year for Composite zone (Varanasi).
\end{abstract}

Keywords: Organic Rankine Cycle; Dry; Wet; Hybrid Cooling Tower; Climate Zone

\section{Abbreviations}

A: area, ; : Specific Heat, Kj/kg-K; : Heat Capacity Ratio; : Specific Enthalpy, Kj/kg; : Heat Transfer Coefficient, W/K; : Mass Transfer Coefficient, kg/; : Enthalpy Of Vaporization, Kj/kg; ITD: Internal Temperature Difference; : Mass Flow Rate, kg/sec;: Thermal Efficiency, \%; : Power of Fan, W; NTU: Number of Transfer Unit; : Pressure Difference, kPa; : Heat Transfer Rate, kW; : Range, ; RH: Relative Humidity, \%; : Temperature, ; : Expander Power Output,
kW; : Specific Humidity; : Effectiveness; : Air; : Air Inlet; : Air Outlet; : Condenser; : Cooling Water; : Cooling Water Inlet; : Cooling Water Outlet; db: Dry Bulb; : Dry Cooling Tower; : Wet Cooling Tower; : Deluge Water; : Evaporator; : Expander; : Heat Transfer Fluid; : Heat Transfer Fluid Inlet; : Heat Transfer Fluid Outlet; : Pump; s: Saturation; T: Total; : Thermal; : Water; wb: Wet Bulb; : Water Inlet; : Water Outlet; : Working Fluid 


\section{Introduction}

In the present era of global warming and energy crisis, the Organic Rankine Cycle (ORC) has the eminent potential to convert low to moderate waste heat into power generation. ORC shows the promising capability to utilization of waste heat from different heat source geothermal, biomass, solar energy, and industrial waste heat [1-4].

Organic Rankine Cycle (ORC) system has been extensively investigated theoretically and experimentally during the last two decades. A modified open drive scroll compressor investigated experimentally with R24fa as the working fluid. The result shows that the maximum expander power and efficiency achieve $2.1 \mathrm{~kW}$ and $8 \%$, respectively, with condensing temperature $50^{\circ} \mathrm{C}$ [5]. A comprehensively study was performed in order to maximize the ORC performance with optimal matching of evaporative and condensation temperature. The geothermal heat source was taken with temperature of $120^{\circ} \mathrm{C}$. The finding of study shows that the ORC performance was maximum at optimal pair of condensing and evaporation temperature. Also, results shows lower sink temperature was preferable for optimum performance [6]. A Simulation study was performed to improve the condenser performance with closed wet cooling tower. The finding of study shows that as pressure loss of wet cooling tower rises then the net power and net efficiency decreases [7]. An experimental study was conducted for micro ORC with piston expander. The range for sources temperature was $65^{\circ} \mathrm{C}$ to $85^{\circ} \mathrm{C}$ and the cold water supply temperature was $18^{\circ} \mathrm{C}$ for winter $22^{\circ} \mathrm{C}$ to $27^{\circ} \mathrm{C}$ for summer. Result shows that the higher cold water temperature reduces the expansion ratio of expander [8]. A matlab code was developed to optimize the recuperated ORC system with air-cooled condenser for design and off design conditions. For the analysis two distinct locations was selected. The optimization results conclude that with the similar design conditions the optimum economic performance can be attain for two locations [9].

An experimental analysis was carried out to analyze the performance of a mini-scale ORC cycle for source temperature range $75^{\circ} \mathrm{C}$ to $95^{\circ} \mathrm{C}$ and sink temperature range $20^{\circ} \mathrm{C}$ to $33^{\circ} \mathrm{C}$. The maximum power output of this system was $1.2 \mathrm{~kW}$ [10]. Liu., et al. [11] studied the effect on condensing temperature on the ORC system with geothermal heat source with source temperature $100-150^{\circ} \mathrm{C}$. In this analysis the cooling temperature was fixed at $20^{\circ} \mathrm{C}$, and the effect of ambient conditions for the cooling tower was not considered.
An economic optimization was performed for the ORC system with geothermal heat as a source. An air-cooled condenser was adopted for the above optimization. The report shows that the performance of the ORC system considerably affects air-cooled condensers [12]. Ghasemi., et al. analyzed the performance of ORC with air-cooled condensers. The results suggest that under varying ambient conditions, the ORC performance can be amplified with proper adjusting of fan speed of dry cooling tower [13].

Walraven., et al. [14] compare the performance of water and aircooled condensers. It is evident from the study that the mechanical draft wet cooling tower is more economical than the air cooling system. The different weather conditions were not included in the above study. Very less attention has been given to the ORC system performance under varying ambient conditions [15]. Muhammad., et al. [16] conduct a Thermo economic comparison of water and air cooling ORC system for different geographic conditions. The organic working fluid R245fa and R1233zde were selected for the comparison. The effect of ambient temperature on ORC system performance was analyzed numerically for air and water-cooled cooling towers. Results suggest that based on ambient temperature variation, the cooling tower suited for the hot and dry region. The author did not consider the weather parameter relative humidity for the comparison. A modeling and experimental investigation were carried out to measure the ORC performance with a scroll expander. The condenser of the ORC system was cooled by a closed spray cooling tower. The finding of this experiment shows that ambient temperature and relative humidity significantly affect ORC performance. Also, the result shows that if the relative humidity increases from $50 \%$ to $90 \%$, the expander output reduces around three times [17]. A potential study of ORC technology was conducted, and it suggests that due to the climatic variation of India, the performance of ORC is very challenging throughout the year [18].

The above literature review shows that very little attention has been given to the effect of cooling tower performance on the ORC system. Also, a minimal study has been conducted on ORC performance with different climatic conditions. Some authors conducted the study on ORC performance with different dry bulb temperature, but the effect of Relative humidity was not analyzed properly. As the relative humidity is effective operational parameter for the wet cooling tower so there is a need to conduct a study to analyze the effect of RH on ORC system performance for a particular place. The study of the effect of hybrid cooling tower on ORC performance 
was also not reported in the literature study. For most of the study, the ambient conditions were fixed at a constant value. But in actual practice, the climatic conditions vary throughout the year, especially the country like India. The design of single ORC system cannot be implemented at every place. So there is a need to analyze the thermal performance of the ORC system for the different cooling towers under varying ambient temperature and relative humidity. So the objective of the present study is to examine the ORC thermal performance for six climatic zones hot and dry (Jodhpur), hot and humid (Mumbai), moderate (Banglore), composite (Varanasi), cold and cloudy (Srinagar) and cold and sunny (Leh) of India. Also, the purpose of this study to find out the thermal performance of the ORC system with dry, wet, and dry/wet (hybrid) cooling towers under varying relative humidity range and ambient temperature range for above six climatic zones of India. This numerical study will help to install an experimental setup of the ORC system with different cooling system at different climatic place of India.

\section{Materials and Methods}

Thermodynamic modeling of ORC

The following assumptions were made for a mathematical analysis of ORC system:

- $\quad$ The vapour and liquid state are at the thermodynamic equilibrium conditions.

- In the evaporator and condenser, the pressure drops are very small and can be neglected.

- The mass flow rate of organic working fluid is constant throughout the cycle.

The Organic Rankine Cycle (ORC) system shown in figure 1 is being contemplated for analysis because of its simple configuration [19]. Liquid organic working fluid passes through the pump and goes to the evaporator of the ORC system. In the evaporator, it gains heat from the heat transfer fluid. As the boiling temperature of the organic fluid is quite low, so the liquid working fluid started converts into vapour, the pressure and temperature of fluid started rising. After this, the working fluid in the vapour form passes through the expander, and the expansion process occurs due to the expansion of vapour refrigerant it's pressure and temperature decreases. As the expansion process begins, the expander starts rotating and able to produce mechanical power. Through the generator the shaft power converted into electrical power. Now the vapour refrigerant travels through the condenser where it rejects heat to the cooling water, which comes from cooling tower. The vapour refrigerant starts condensing and converts into the liquid state as working fluid rejects its latent heat to the cooling water. Organic working fluid should have low Ozone depletion potential (ODP) and Global warming potential (GWP) and best thermodynamic performance capability with the ORC system. On the basis of such properties, working fluid R24fa has been selected for the thermal analysis [2022]. The physical properties of R24fa are given in table 1 . Design and operational parameters have been selected for the thermodynamic simulation from the works of [23].

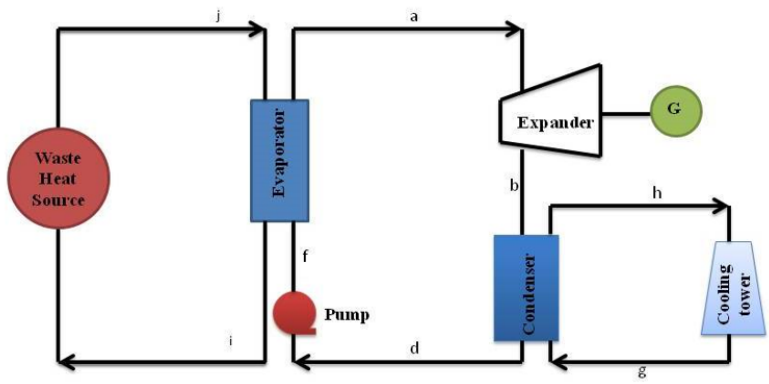

Figure 1: Layout of the ORC system.

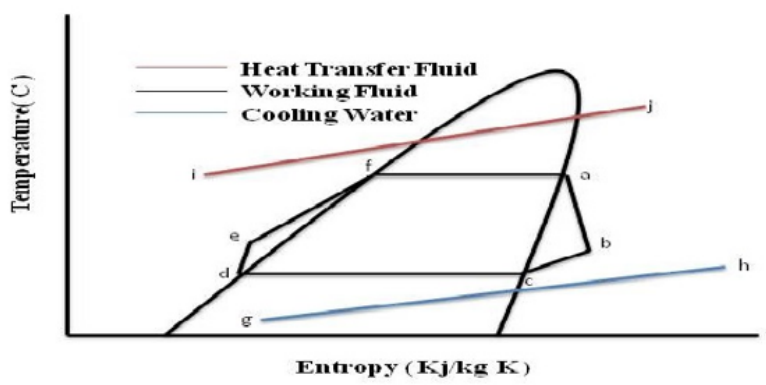

Figure 2: T-s diagram of R245fa working fluid.

The mass and energy conservation equation are applied for the ORC system to examine the performance of ORC.

Heat transfer to the evaporator of ORC is given by Eq. (1)

$$
Q_{\text {eva }}=m_{w f} \cdot\left(h_{a}-h_{e}\right)=m_{h t f} \cdot C_{p, h t f} \cdot\left(T_{i, h t f}-T_{o, h t f}\right)
$$


Thermodynamic Analysis of Small Scale Organic Rankine Cycle (ORC) System Based on Dry, Wet and Dry/Wet (Hybrid) Cooling Towers Under Six Climatic Zones of India

Expander power output of the ORC system is given by Eq. (2)

$\mathrm{W}_{\exp }=\mathrm{n}_{\exp } \cdot\left(\mathrm{h}_{\mathrm{a}}-\mathrm{h}_{\mathrm{b}}\right)-----(2)$

Pump power of the ORC unit is given by Eq. (3)

$\mathrm{W}_{\mathrm{p}}=\mathrm{n}_{\mathrm{p}} \cdot\left(\mathrm{h}_{\mathrm{e}}-\mathrm{h}_{\mathrm{d}}\right)--------(3)$

The condenser heat rejected is given by Eq. (4)

$\mathrm{Q}_{\text {cond }}=\mathrm{m}_{\mathrm{wf}} \cdot\left(\mathrm{h}_{\mathrm{b}}-\mathrm{h}_{\mathrm{d}}\right)=\mathrm{m}_{\mathrm{cw}} \cdot \mathrm{C}_{\mathrm{p}, \mathrm{w}} \cdot\left(\mathrm{T}_{\mathrm{i}, \mathrm{cw}}-\mathrm{T}_{\mathrm{o}, \mathrm{cw}}\right)$

The net power output of the ORC system is given by Eq. (5)

$\mathrm{W}_{\text {net }}=\mathrm{W}_{\exp }-\mathrm{W}_{\mathrm{p}}-----(5)$

The thermal efficiency of the ORC system is given by Eq. (6)

$\mathrm{n}_{\mathrm{th}}=\frac{\mathrm{w}_{\text {net }}}{Q_{\text {eva }}}-----(6)$

\begin{tabular}{|l|c|}
\hline Boiling point [K] & 288.29 \\
\hline Critical temperature [K] & 427.16 \\
\hline Critical pressure [MPa] & 3.651 \\
\hline Molecular formula & CF3CH2CH2 \\
\hline Fluid type & dry \\
\hline GWP & 950 \\
\hline ODP & 0 \\
\hline Decomposition pressure [MPa] & 200 \\
\hline Decomposition temperature [K] & 440 \\
\hline Ignitability & NO \\
\hline
\end{tabular}

Table 1: Physical Properties of Organic Fluid R245fa [22].

\begin{tabular}{|l|c|}
\hline Evaporator load $(\mathrm{kW})$ & 38 \\
\hline Expander Power Output $(\mathrm{kW})$ & 3 \\
\hline Isentropic efficiency of the expander $(\%)$ & 75 \\
\hline Mass flow rate of organic working fluid $(\mathrm{kg} / \mathrm{sec})$ & 0.101 \\
\hline Source Temperature $\left({ }^{\circ} \mathrm{C}\right)$ & 100 \\
\hline Temperature of heat transfer fluid $\left({ }^{\circ} \mathrm{C}\right)$ & 120 \\
\hline
\end{tabular}

Table 2: Design and Operational parameter of the ORC system for simulation [23].

\section{Weather data of different climatic zone of India}

India possesses varying climatic conditions throughout the year, ranging from extremely cold climatic zones to severely hot conditions. On the basis of diverse climatic conditions, India divided into six climatic zones (1) Hot and dry (2) Warm and humid (3) Moderate (4) Composite (5) Cold and cloudy (6) Cold and sunny. For the present simulation study the different city from each zone, Jodhpur (Hot and dry), Mumbai (Warm and humid), Banglore (Moderate), Varanasi (Composite), Leh (Cold and sunny) and Srinagar (Cold and cloudy) was selected [23] for the study. The averaged monthly weather data ambient temperature and relative humidity were taken from [24].

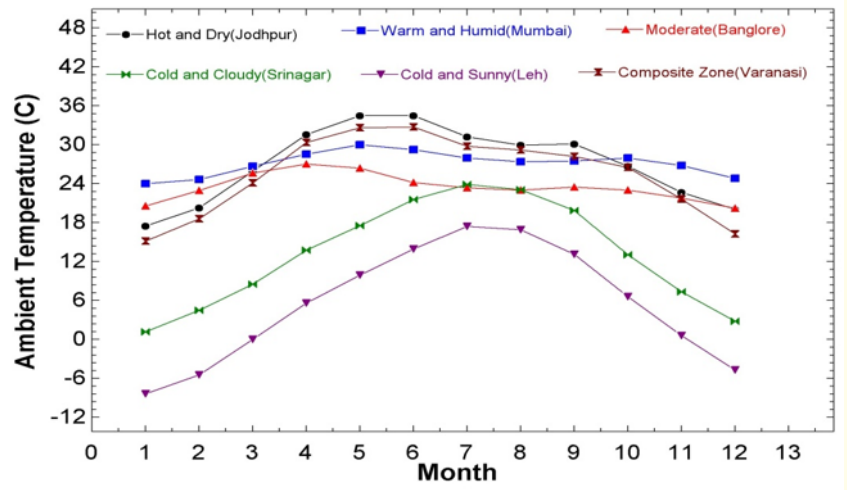

Figure 3: Monthly ambient temperature variation of six climatic zones.

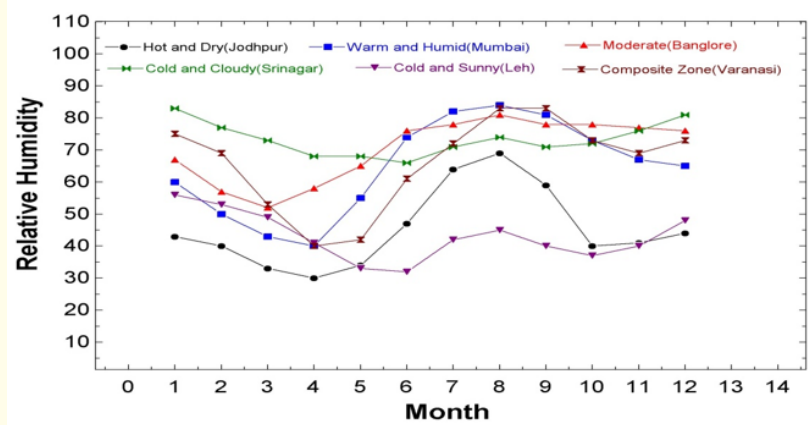

Figure 4: Monthly relative humidity variation of six climatic zones. 
Figure 3 and figure 4 shows the averaged monthly ambient temperature and relative humidity variation for the different climatic zone. For the simulation study, the monthly ambient temperature and $\mathrm{RH}$ range of each zone were considered to prognosticate the ORC performance with different cooling tower mode. In Jodhpur and Mumbai, 7 months and 10 months can be considered as hot and dry and warm and humid conditions, respectively. For the Banglore 10 months are considered warm and humid. In the cold region, Srinagar and Leh 8 months and 12 months prevail to the cold and cloudy and cold and sunny conditions. Varanasi falls under the composite zone; it means previously condition not prevail for more than six months.

\section{Modeling of cooling tower}

In this simulation study a mathematical model of dry, wet, and dry/wet (hybrid) were analyzed to predict the performance of the ORC system, with different modes of the cooling tower. The operational parameter ambient temperature and relative humidity range of each zone were taken for the analysis of three cooling towers.

\section{Dry Cooling tower}

The effectiveness-NTU method is appropriate for the dry cooling tower analysis as it predicts the quite accurate outlet temperature of air and water for a specific heat exchanger [25]. The structure of the dry section is fin and tube type, heat exchanger. The air flows across the section, and water flows inside the tube of the heat exchanger. The maximum water can be cooled up to ambient air temperature. The air and water do not mix. Heat transfer for air and waterside can be evaluated as:

$$
\begin{aligned}
& \mathrm{Q}_{\mathrm{air}}=\mathrm{m}_{\mathrm{dry}} \mathrm{C}_{\mathrm{pa}}\left(\mathrm{T}_{\mathrm{ao}}-\mathrm{T}_{\mathrm{ai}}\right)----(7) \\
& \mathrm{Q}_{\mathrm{w}}=\mathrm{m}_{\mathrm{w}} \mathrm{C}_{\mathrm{pw}}\left(\mathrm{T}_{\mathrm{wi}}-\mathrm{T}_{\mathrm{wo}}\right)---(8)
\end{aligned}
$$

Where $Q_{\text {air }}$ and $Q_{w}$ are the heat transfer rate for air and water streams, respectively.

The effectiveness of heat exchanger can be defined as:

$$
\begin{aligned}
& \varepsilon=\frac{\mathrm{m}_{\mathrm{w}} \cdot \mathrm{C}_{\mathrm{pw}}\left(\mathrm{T}_{\mathrm{wi}}-\mathrm{T}_{\mathrm{wo}}\right)}{\mathrm{m}_{\mathrm{dry}} \cdot \mathrm{C}_{\mathrm{pa}}\left(\mathrm{T}_{\mathrm{wi}}-\mathrm{T}_{\mathrm{ai}}\right)}=\frac{\mathrm{C}_{\mathrm{w}} \cdot \mathrm{R}}{\mathrm{C}_{\mathrm{a}} \cdot \mathrm{ITD}}--(9) \\
& \varepsilon=1-\exp \left[\left(\frac{1}{\mathrm{C}_{\mathrm{r}}}\right)\left(\mathrm{NTU}^{0.22}\right)\left\{\exp \left[-\mathrm{C}_{\mathrm{r}}\left(\mathrm{NTU}^{0.78}\right)\right]-1\right\}\right](10)
\end{aligned}
$$

$\mathrm{NTU}=\frac{\mathrm{U} \cdot \mathrm{A}}{\mathrm{C}_{\mathrm{a}}}---(11)$

Wet cooling tower

In this section, for the energy transfer between the air and water, a closed spray cooling tower was adopted for the modeling. Through the tubes, the cooling water passed. The deluge water sprinkling from the top portion of the tubes and air comes into contact with the sprayed water from the opposite side. The total heat transfer during the process is the summation of heat transfer from deluge water to the air and cooling water through tubes and deluge water, and heat transfer due to deluge water evaporation. The maximum water can be cooled up to the dew point temperature.

The heat transfer between the air and deluge water is given in Eq. 12. [26].

$\mathrm{Q}_{\mathrm{a}}=\mathrm{h}_{\mathrm{c}} \mathrm{A}\left(\mathrm{T}_{\mathrm{dw}}-\mathrm{T}_{\mathrm{a}}\right)+\mathrm{i}_{\mathrm{v}} \mathrm{h}_{\mathrm{d}} \mathrm{A}\left(\omega_{\mathrm{s}}-\omega\right)-----(12)$

In the above equation, the convective heat transfer between the air and deluge water is represented by the first term of the righthand side and can be expressed as:

h.A. $\left(\mathrm{T}_{\mathrm{dw}}-\mathrm{T}_{\mathrm{a}}\right)=\mathrm{m}_{\mathrm{a}} \cdot \mathrm{C}_{\mathrm{pa}} \cdot\left(\mathrm{T}_{\mathrm{ao}}-\mathrm{T}_{\mathrm{ai}}\right)---$

The evaporative heat transfer of deluge water is expressed by the second term of eq. (12) and is shown as:

$h_{d} \cdot A\left(\omega_{s}-\omega\right) i=m_{a}\left(\omega_{o}-\omega_{i}\right)---(14$

The heat transfer between the deluge water and the cooling water inside the tube can be represented as:

$\mathrm{Q}_{\mathrm{cw}}=\mathrm{m}_{\mathrm{cw}} \cdot \mathrm{C}_{\mathrm{p}, \mathrm{cw}} \cdot\left(\mathrm{T}_{\mathrm{cw}, \mathrm{i}}-\mathrm{T}_{\mathrm{cw}, \mathrm{o}}\right)-----$

Table 3 represents the different correlation and parameter used for the given equations [27-29].

Dry/wet (hybrid) cooling tower

Hybrid cooling tower consists of various ranges of arrangements, and it was summarised by Streng., et al. [30]. The study suggests that the Parallel Path wet/dry (PPWD) tower is the most efficient configuration for the cooling process. In this combined arrangement, the water through the series and air passes parallel for dry and wet parts of the system. 
Thermodynamic Analysis of Small Scale Organic Rankine Cycle (ORC) System Based on Dry, Wet and Dry/Wet (Hybrid) Cooling Towers Under Six Climatic Zones of India

\begin{tabular}{|l|c|}
\hline Parameter & Expressions \\
\hline $\begin{array}{l}\text { Out-tube convective heat transfer } \\
\text { Coefficient }\left(\mathrm{W} / \mathrm{m}^{2} \mathrm{~K}\right)\end{array}$ & $h_{o}=704\left(1.39+0.022 . T_{w}\right)\left(\frac{m_{w}}{d_{o}}\right)^{1 / 3}$ \\
\hline $\begin{array}{l}\text { In-tube convective heat transfer coefficient } \\
\left(\mathrm{W} / \mathrm{m}^{2} \mathrm{~K}\right)\end{array}$ & $h_{i}=0.023 \frac{s_{p}}{d_{i}} R^{0.8} \operatorname{Pr}^{0.3}$ \\
\hline $\begin{array}{l}\text { Overall heat transfer coefficient } \\
\left(\mathrm{W} / \mathrm{m}^{2} \mathrm{~K}\right)\end{array}$ & $\frac{1}{K}=\frac{1}{h_{i}} \cdot \frac{d_{o}}{d_{i}}+r_{i} \frac{d_{o}}{d_{i}}+\frac{d_{o}}{s_{p}} \ln \frac{d_{o}}{d_{i}}+r_{o}+\frac{1}{h_{o}}$ \\
\hline $\begin{array}{l}\text { Mass transfer coefficient } \\
\left(\mathrm{kg} / \mathrm{m}^{2}\right)\end{array}$ & $h_{d}=0.049 . G_{m a}^{0.905}$ \\
\hline Lewis factor & $L e=\frac{h}{C_{p a} h_{d}}=1$ \\
\hline Saturated pressure $(\mathrm{Pa})$ & $P_{n}=611.2 e^{\frac{\left(18.678-\frac{T}{234.5}\right.}{T+257.14}}$ \\
\hline Moisture content $(\%)$ & $\omega=0.6219 \frac{0.01 H_{r} \cdot P_{v}}{101326-0.01 H_{r} \cdot P_{v}}$ \\
\hline Enthalpy of the moist air $(\mathrm{Kj} / \mathrm{kg})$ & $H_{\text {air }}=1.01 . T_{d}+\left(2500+1.84 . T_{d}\right) \omega$ \\
\hline
\end{tabular}

Table 3: Correlation and parameter for wet cooling tower.

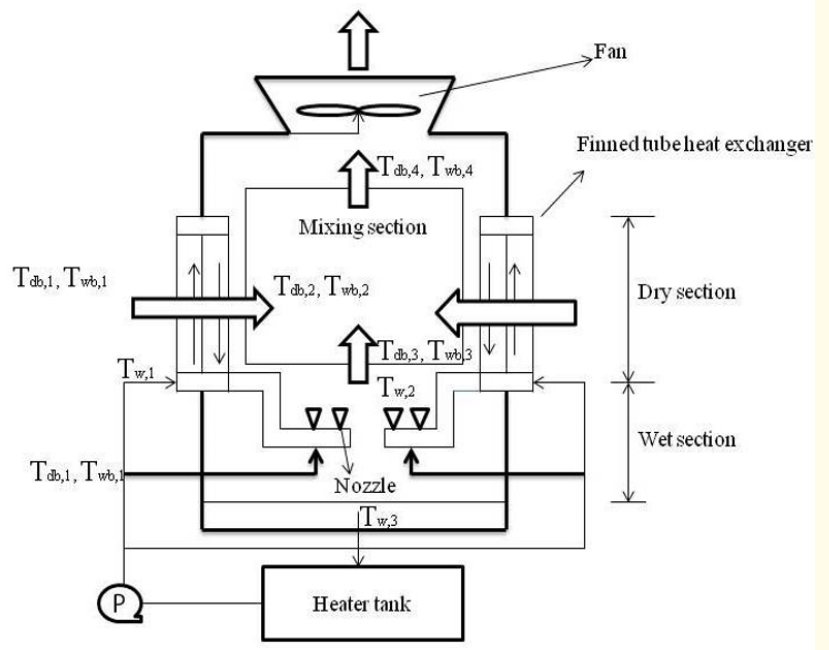

Figure 5: Schematic diagram of the hybrid cooling tower.

Figure 5 shows the schematic diagram of the hybrid cooling tower. The air is passing through the dry and wet section through a parallel path. An induced fan was incorporated at the top portion to draw the air from both sections. In the dry section, the water is cooled with ambient air. The water passes through the tubes of finned and tube heat exchanger, and air crosses the heat exchanger. So the range of dry section is the difference between the cooling water inlet and outlet temperature. After that, cooling water passes through the wet section where it comes in direct contact to the ambient air and cools to the temperature. The range of wet section is the difference between the temperature of cooling water at the outlet of dry section and. The total range of the hybrid cooling tower is the summation of dry section cooling range and wet section cooling range. In the mixing section, the hot and humid air and hot and dry air mixes from wet section and dry section part of a hybrid cooling tower. So the discharged state of air is as uniform as possible. No plume is formed as the ambient air mixed with discharged air. The hybrid cooling towers combines the benefit of both dry and wet cooling tower. The incorporation of a dry cooling tower is for the high inlet temperature of cooling water and decrease the water consumption. Also, the plume formation is eliminated. The wet section was adopted to maintain the efficiency of the cooling tower.

The law of conservation of mass and energy is applied to the mixing section as given by [31]. 


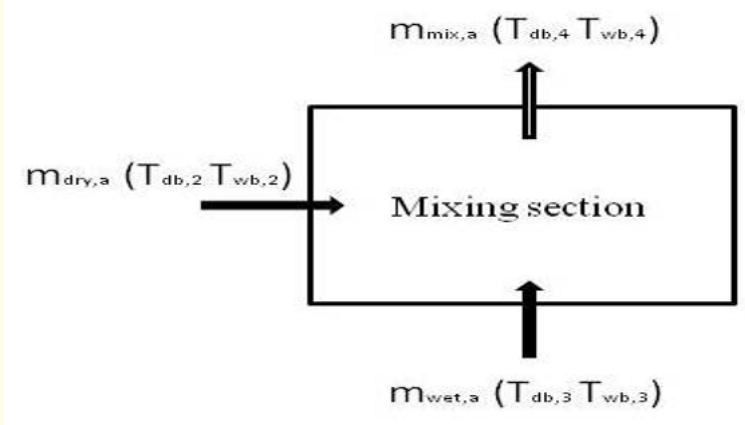

Figure 6: Mixing section of hybrid cooling tower.

Mass of dry air

$\mathrm{m}_{4}=\mathrm{m}_{\mathrm{T}}=\mathrm{m}_{\mathrm{dct}}+\mathrm{m}_{\mathrm{wct}}----(16)$

Mass of water vapour

$\mathrm{m}_{\mathrm{T}} \omega_{4}=\mathrm{m}_{\mathrm{dct}} \omega_{2}+\mathrm{m}_{\mathrm{wct}} \omega_{3}---(17)$

Energy balance

$\mathrm{m}_{\mathrm{T}} \mathrm{h}_{4}=\mathrm{m}_{\mathrm{dct}} \mathrm{h}_{2}+\mathrm{m}_{\mathrm{wct}} \mathrm{h}_{3}----(18)$

By combining the above equation we get

$\frac{\mathrm{m}_{\mathrm{wct}}}{\mathrm{m}_{\mathrm{T}}}=1-\frac{\mathrm{m}_{\mathrm{dct}}}{\mathrm{m}_{\mathrm{T}}}=\frac{\mathrm{h}_{4}-\mathrm{h}_{2}}{\mathrm{~h}_{3}-\mathrm{h}_{2}}=\frac{\omega_{4}-\omega_{2}}{\omega_{3}-\omega_{2}}------(19)$

For the hybrid cooling mode, the ratio $\frac{\mathrm{m}_{\mathrm{wct}}}{\mathrm{m}_{\mathrm{T}}}$ shows the average property value. For the wet cooling mode, its value is 1 , and for the dry cooling mode is 0 . The range is 0 to 1 for the hybrid cooling mode. Also, the ratio of heat rejection in wet mode to the total heat rejection can be express as:

$\frac{\mathrm{Q}_{\mathrm{wct}}}{\mathrm{Q}_{\mathrm{T}}}=1-\frac{\mathrm{Q}_{\mathrm{dct}}}{\mathrm{Q}_{\mathrm{T}}}=\frac{\frac{\mathrm{m}_{\mathrm{dct}}}{\mathrm{m}_{\mathrm{T}}}\left(\mathrm{h}_{3}-\mathrm{h}_{1}\right)}{\frac{\mathrm{m}_{\mathrm{dct}}}{\mathrm{m}_{\mathrm{T}}} \mathrm{h}_{3}+\left(1-\frac{\mathrm{m}_{\mathrm{wct}}}{\mathrm{m}_{\mathrm{T}}}\right) \mathrm{h}_{2}-\mathrm{h}_{1}}----(20)$

\section{Condenser model}

In the condenser, the vapour refrigerant condenses into the liquid state as the latent heat of absorption released. The cooling wa- ter from the cooling tower passes through condenser and exchange heat transfer with vapour refrigerant, and it starts condensing. During the expansion process in the expander, the pressure drops from high to low. The expander backpressure is the function of condensing temperature.

The energy conservation applies to the condenser and gives as:

$\mathrm{m}_{\mathrm{w}} \cdot\left(\mathrm{h}_{\mathrm{b}}-\mathrm{h}_{\mathrm{d}}\right)=\mathrm{m}_{\mathrm{cw}} \cdot \mathrm{C}_{\mathrm{P}, \mathrm{w}} \cdot\left(\mathrm{T}_{\mathrm{cw}, \mathrm{i}}-\mathrm{T}_{\mathrm{cw}, \mathrm{o}}\right)----(21)$

$h_{b}$ and $h_{d}$ are the enthalpies of the refrigerant at the entrance and exit of the condenser. The mass flow rate of cooling water is and the cooling water inlet and outlet temperature are and respectively. The backpressure at the expander end is affected by the cooling water temperature. The cooling water temperature depends upon the ambient temperature. So the back pressure of expander rises when the cooling water temperature increases.

The fans' shaft power is represented as [32].

$\frac{\mathrm{N}_{\mathrm{fan}=} \mathrm{m}_{\mathrm{a}} \Delta \mathrm{p}}{3.6 \times 10^{6} \mathrm{n}_{\mathrm{fan}}}$

where $\mathrm{m}_{\mathrm{a}}$ the mass flow rate of air is, $\mathrm{n}_{\mathrm{fan}}$ is the efficiency of the fan, $\Delta \mathrm{p}$ increase in pressure pass through the fan, and the fan shaft power is given by $\mathrm{N}_{\text {fan }}$. In the simulation, the $\mathrm{n}_{\text {fan }}$ fan efficiency is assumed to be constant. The entrance and exit conditions of air considered different for various climatic zones.

\section{Results and Discussion}

A thermodynamic analysis of the ORC system was conducted in six climatic zones with different dry, wet, and hybrid cooling mode. A mathematical model was developed in the Engineering equation solver (EES) software environment. The design and operational parameters for the ORC system were fixed for each climatic zone. The shaft output was $3 \mathrm{~kW}$, and the source temperature was fixed 100 for each zone. The sink condition varies with different environmental conditions. The cooling tower range was fixed 10 for every zone. In the hybrid cooling tower, $80 \%$ of the cooling load was shared by the wet section. As the climatic conditions of each zone are different, so relative humidity and ambient temperature range were varied according to the zone for the analysis. 
Effect of relative humidity and ambient temperature on ORC performance - Jodhpur (Hot and Dry conditions)

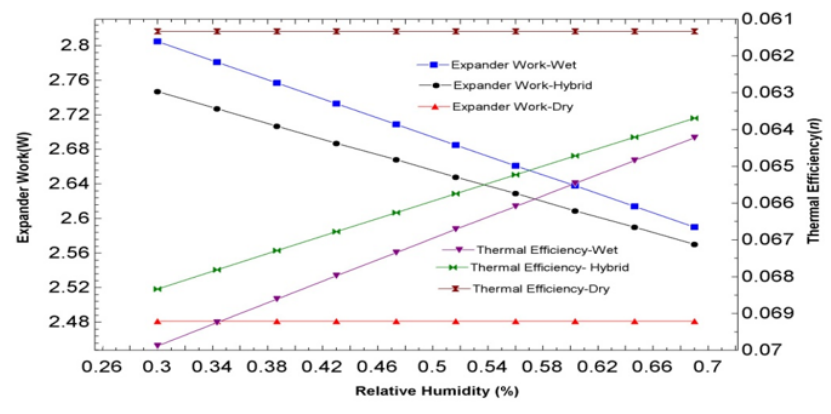

Figure 7: Effect of relative humidity on expander work and thermal efficiency (Jodhpur).

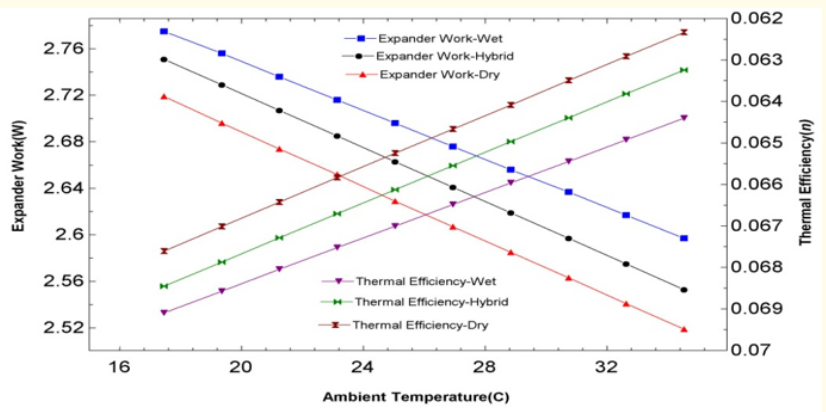

Figure 8: Effect of ambient temperature on expander work and thermal efficiency (Jodhpur).

The effect of monthly averaged relative humidity and ambient temperature on the power output and thermal efficiency is shown in figure 7, and figure 8. In order to analyze the humidity effect, the relative humidity varies from minimum to maximum from $30 \%$ (April) to 69\% (August), respectively. The ambient temperature was fixed to the 34.52 . The cooling temperature range was fixed to 10 . When the relative humidity varies from $30 \%$ to $69 \%$ then the cooling water outlet temperature (increases from 28.84 to 35.6 for wet cooling mode and 38.44 to 40.16 for the hybrid mode. There is no effect of relative humidity for the dry cooling mode. Due to the increase in the cooling water outlet temperature, the condensing temperature and backpressure of expander increase and power output is decreased. So when the RH increases from $30 \%$ to $69 \%$, the expander power ( decreases from $2.805 \mathrm{~kW}$ to 2.59 $\mathrm{kW}(7.664 \%)$ for wet mode and $2.747 \mathrm{~kW}$ to $2.57 \mathrm{~kW}(6.443 \%)$ for hybrid mode respectively. The output for the dry cooling mode was fixed at $2.481 \mathrm{~kW}$. The thermal efficiency ( of ORC for wet mode decreases from $6.988 \%$ to $6.422 \%(8.002 \%)$ and $6.833 \%$ to $6.369 \%$ $(6.88 \%)$ for hybrid mode. ORC system efficiency with a dry system was $6.133 \%$. These results can be validated with the finding of ref [16]. Results show that the thermal performance of the hybrid cooling tower is between the two, which are similar findings of ref [30]. The monthly ambient temperature was varied from 17.45(January) to 34.52 (May) with a fixed relative humidity of $60 \%$. When the ambient temperature rises from 17.45 to 34.52 the cooling water temperature outlet rises from 31.94to 34.02 for wet cooling mode and from 38.04 to 39.48 for hybrid mode. So the backpressure of the expander increases. The shaft power ( of the ORC system decreases from $2.775 \mathrm{~kW}$ to $2.597 \mathrm{~kW}(6.414 \%)$ for wet cooling mode and $2.751 \mathrm{~kW}$ to $2.553 \mathrm{~kW}$ (7.924\%) for hybrid mode. For the above ambient temperature range, the expander power (decreases from $2.719 \mathrm{~kW}$ to $2.519 \mathrm{~kW}$ (7.335\%) for dry cooling mode as the condensing temperature and backpressure increases. The thermal efficiency ( of ORC decreases from $6.909 \%$ to $6.440 \%$ (6.778\%), $6.845 \%$ to $6.324 \%$ (7.611\%), and $6.760 \%$ to $6.233 \%$ (7.795\%) for wet, hybrid and dry cooling mode respectively. This finding can be validated with the ref $[15,16]$. The study finds that at high relative humidity with fixed high ambient temperature, the performance of ORC with wet cooling mode degrades significantly. At the high humidity, the evaporation heat transfer decreases, which leads to a reduction in the performance of a wet cooling tower. At high ambient temperature with fixed relative humidity, the dry cooling performance degrades more than other cooling modes. As the Rajasthan is the driest state of India and surface water resources are limited in Jodhpur. Even though the high performance of ORC with wet mode dry cooling is preferred for this zone. The hybrid cooling tower has the capability to reduce water consumption. So with proper design with maximum cooling load with dry cooling section could be implemented. 
Effect of RH and ambient temperature on ORC performance Mumbai (Warm and humid conditions)

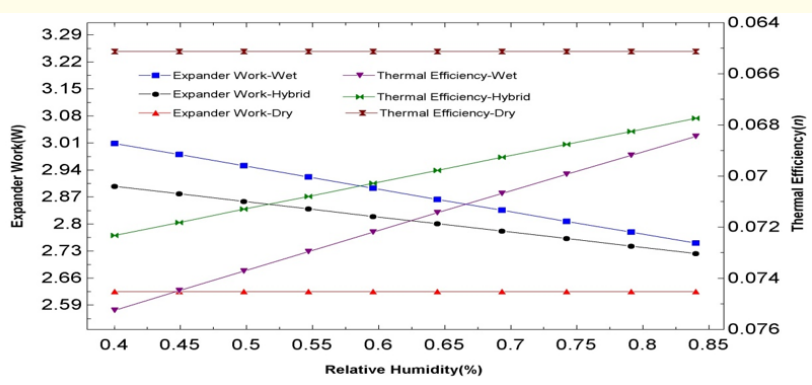

Figure 9: Influence of RH on expander work and thermal efficiency.

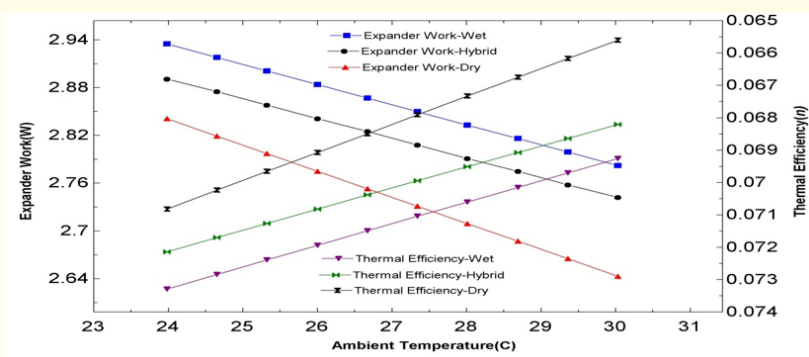

Figure 10: Effect of ambient temperature on expander work and thermal efficiency.

The effect of monthly averaged relative humidity and ambient temperature on ORC performance with the different cooling modes is shown in figure 9 and figure 10. As compare to Jodhpur, the humidity of Mumbai is high and varies from $40 \%$ (April) to a maximum of $84 \%$ (August). The monthly ambient temperature is lower than the Jodhpur and varies from the 23.98(January) to 30.03 (May). As the relative humidity varies from $40 \%$ to $84 \%$ at a fixed ambient temperature 30.03 the cooling water outlet temperature increases from 26.31 to 33.7 and 34.24 to 37.31 for wet and hybrid cooling towers. Due to this, the backpressure of expander increases. The expander output reduces from $3.009 \mathrm{~kW}$ to $2.751 \mathrm{~kW}(8.574 \%)$ and $2.898 \mathrm{~kW}$ to $2.724 \mathrm{~kW}$ (6.004\%), respectively. The expander power of ORC for the dry cooling tower was $2.625 \mathrm{~kW}$ as no effect of RH on dry cooling mode. The efficiency of ORC with a wet system and hybrid system reduces $7.525 \%$ to $6.844(9.044 \%)$ and $7.232 \%$ to $6.774 \%$ (6.332\%). ORC system ef- ficiency was $6.332 \%$ for dry cooling mode. As the humidity range of Mumbai is higher than the Jodhpur, so thermal efficiency degrades $9.049 \%$ as compared to $8.002 \%$ with wet cooling mode. Also, a dry cooling tower was not affected by variation in relative humidity. For this zone, the monthly ambient temperature was varied from 23.98(January) to 30.03 (May), and relative humidity was fixed at $60 \%$. When the monthly ambient temperature varies from 23.98 to 30.03 the cooling water outlet temperature increases form 28.71 to 29.64 for wet mode and 34.2 to 34.99 for hybrid mode. As the cooling water temperature rises, the backpressure starts increases. The work output of the expander of ORC decreases from $2.935 \mathrm{~kW}$ to $2.782 \mathrm{~kW}(5.212 \%)$ and $2.891 \mathrm{~kW}$ to $2.742 \mathrm{~kW}$ (5.153\%). The ORC work output for dry cooling mode decreases from $2.841 \mathrm{~kW}$ to $2.643 \mathrm{~kW}(6.969 \%)$. The thermal efficiency of ORC decreases form $7.329 \%$ to $6.926 \%$ (5.498\%), $7.214 \%$ to $6.82 \%$ (5.461\%) and $7.082 \%$ to $6.56 \%$ (7.370\%). The ambient temperature of Jodhpur is higher than the Mumbai, so at higher temperature, thermal efficiency degrades much more for Jodhpur.

Effect of RH and ambient temperature on ORC performance Banglore (Moderate conditions)

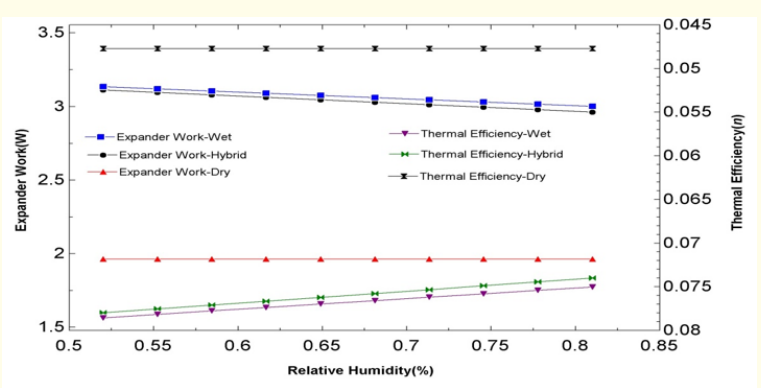

Figure 11: Influence of RH on expander work and thermal efficiency.

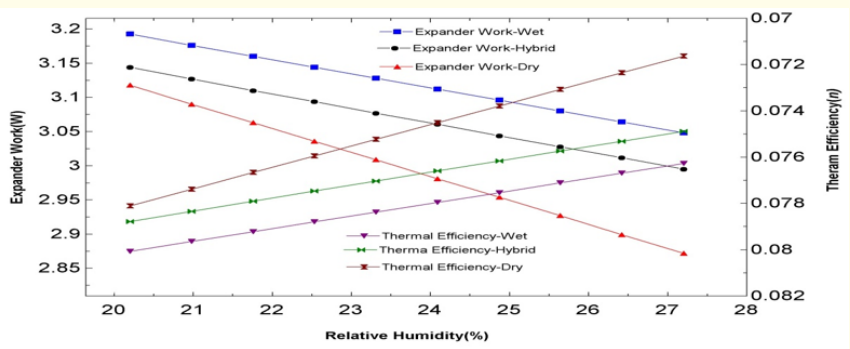

Figure 12: Effect of ambient temperature on expander work and thermal efficiency. 
The Banglore is the moderate zone and figure 11, and figure 12 shows the ORC performance with relative humidity and ambient temperature. The range of $\mathrm{RH}$ for this zone is $52 \%$ (March) to $81 \%$ (August), and ambient temperature varies from 20.22 (December) to 27.01 (April). When the relative humidity varies from minimum (52\%) to maximum(81\%) at fixed ambient temperature 27.01 , the cooling water outlet temperature increases from 25.39 to 30.23 and 31.29 to 33.66 for wet and hybrid cooling tower respectively. ORC expander power decreases from $3.135 \mathrm{~kW}$ to $3.001 \mathrm{~kW}$ $(4.274 \%)$ with wet cooling mode and from $3.113 \mathrm{~kW}$ to $2.962 \mathrm{~kW}$ (4.850\%) with hybrid mode. The expander power was $2.345 \mathrm{~kW}$ with dry mode operation. For the wet and hybrid mode, the ORC thermal efficiency decreases from $7.798 \%$ to $7.502 \%(4.506 \%)$ and $7.856 \%$ to $7.400 \%$ (5.8\%). The thermal efficiency of ORC was $6.171 \%$ for dry mode operation. As the ambient temperature increases from 20.22 to 27.01 at fixed relative humidity $60 \%$, the expander power decreases from $3.193 \mathrm{~kW}$ to $3.048 \mathrm{~kW}$ (4.541\%) and $3.144 \mathrm{~kW}$ to $2.995 \mathrm{~kW}$ (4.739\%) for the wet and hybrid mode of cooling. The reason behind this the cooling water outlet temperature increases from 25.49 to 26.75 and 30.84 to 31.62 for wet and hybrid mode. Also, the backpressure increases when the ambient temperature increases from 20.22 to 27.01 for the dry condition, so the expander power decreases from $3.118 \mathrm{~kW}$ to 2.872 $\mathrm{kW}$ (7.889\%). The thermal efficiency of ORC reduces for wet, hybrid, and dry modes were $8.007 \%$ to $7.627 \%$ (4.745\%), $7.878 \%$ to $7.488 \%$ (4.950\%), and $7.180 \%$ to $7.163 \%$ (8.284\%) respectively. A small temperature ranges of minimum 20.02(December) to a maximum of 27.01(April) for the Banglore throughout the year, so ORC performs better from Jodhpur and Mumbai.

Effect of RH and ambient temperature on ORC performance Varanasi (Composite conditions)

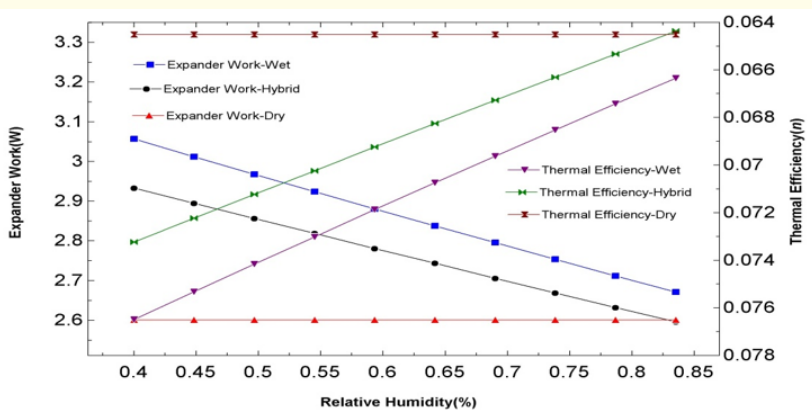

Figure 13: Influence of RH on expander work and thermal efficiency.

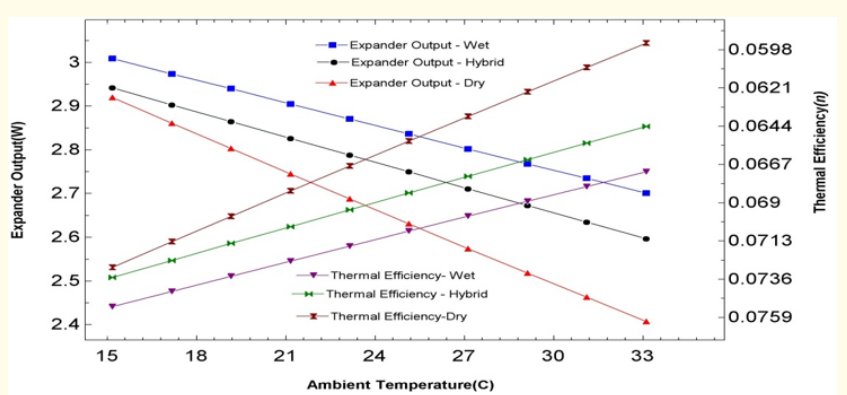

Figure 14: Effect of ambient temperature on expander work and thermal efficiency.

Figure 13, and figure 14 shows the effect of $\mathrm{RH}$ and ambient temperature on ORC performance for the Varanasi (Composite zone). For this zone, the monthly averaged relative humidity varies from $40 \%$ (April) to $83.33 \%$ (September, July), and monthly averaged ambient temperature varies from 15.17 (June) to 32.76(June, May). When the relative humidity varies from the $40 \%$ to $83.33 \%$ with the fixed ambient temperature at 32.76 the expander work of ORC decreases from $3.057 \mathrm{~kW}$ to $2.671 \mathrm{~kW}(12.626 \%)$ and 2.933 $\mathrm{kW}$ to $2.596 \mathrm{~kW}(11.489 \%)$ for the wet and hybrid conditions. The expander work with dry cooling mode was $2.601 \mathrm{~kW}$. The decrement in thermal efficiency of the ORC cycle for the wet and hybrid mode was $7.649 \%$ to $6.634 \%$ (13.269\%) and $7.323 \%$ to $6.436 \%$ (12.11\%), respectively. ORC system thermal efficiency with dry mode was $6.451 \%$. When the ambient temperature increases from 15.17to 32.76, the power output from the expander of ORC starts decreasing from the $3.009 \mathrm{~kW}$ to $2.701 \mathrm{~kW}(10.235 \%)$ and 2.942 $\mathrm{kW}$ to $2.597 \mathrm{~kW}(11.72 \%)$ for wet cooling and hybrid cooling mode. The decrement in the power output of the expander for dry cooling mode was from $2.92 \mathrm{~kW}$ to $2.407 \mathrm{~kW}$ (17.568\%). Also, for wet, hybrid, and dry cooling mode, the decrement in the thermal efficiency of ORC was $7.524 \%$ to $6.713 \%$ (10.778\%), $7.348 \%$ to $6.44 \%$ $(12.357 \%)$ and $7.288 \%$ to $5.94 \%(18.496 \%)$ respectively. The ORC performance in the composite zone varies drastically for minimum and maximum values of $\mathrm{RH}$ and ambient temperature as it varies largely throughout the year.

Effect of RH and ambient temperature on ORC performance Srinagar (Cold and cloudy conditions)

(Figure 15,16) 


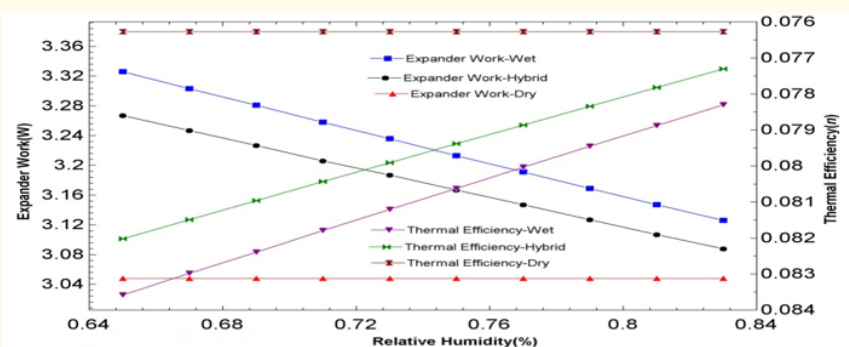

Figure 15: Influence of RH on expander work and thermal efficiency.

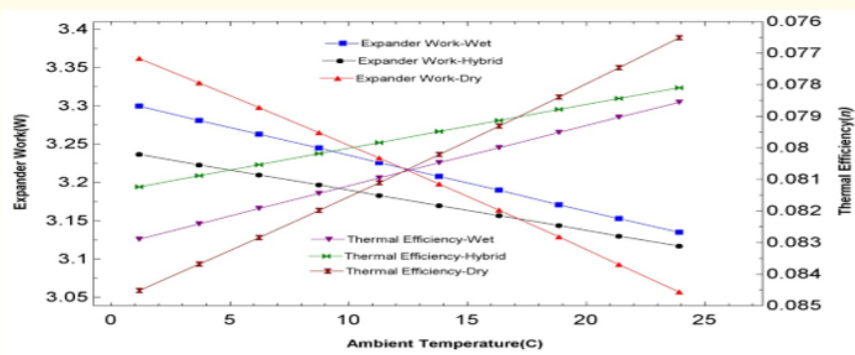

Figure 16: Effect of ambient temperature on expander work and thermal efficiency.

The effect of monthly averaged relative humidity and ambient temperature on the ORC performance with different cooling modes wet, hybrid, and dry mode is shown in figure 15 and figure 16 . The $\mathrm{RH}$ and ambient temperatures vary from $65.75 \%$ (June) to $83 \%$ (January) and 1.171 (January) to 23.90 (July) for this zone. When the relative humidity varies from $65.75 \%$ to $83 \%$ at a fixed ambient temperature of 23.90the power output of expander decreases from $3.326 \mathrm{~kW}$ to $3.126 \mathrm{~kW}$ (6.013\%) for wet mode and $3.267 \mathrm{~kW}$ to $3.088 \mathrm{~kW}(5.509 \%)$ for hybrid mode. For the dry mode, the expander power output was $3.048 \mathrm{~kW}$. The ORC thermal efficiency reduces from $8.358 \%$ to $7.830 \%$ (6.317\%) and $8.202 \%$ to $7.730 \%$ $(5.754 \%)$ for the wet and hybrid mode of the cooling tower. The thermal efficiency of ORC was $7.627 \%$ with dry mode. As the ambient temperature rises from 1.171 to 23.90 with a fixed relative humidity of 70\%, the expander power starts decreasing from the 3.30 $\mathrm{kW}$ to $3.135 \mathrm{~kW}$ (5.00)\% and $3.237 \mathrm{~kW}$ to $3.117 \mathrm{~kW}$ (3.707\%) with wet and hybrid mode. The expander power for dry mode reduces from 3.362 to $3.057 \mathrm{~kW}$. The thermal efficiency starts reducing from $8.289 \%$ to $7.855 \%$ (5.235\%) with wet mode and from $8.123 \%$ to $7.809 \%$ (3.856\%) with hybrid mode. The reduction in thermal efficiency with mode was from $8.452 \%$ to $7.651 \%$ (9.477\%). The results also show that the ORC performance was better with dry cooling mode below the ambient temperature around 11. At the low temperature with fixed high humidity of $70 \%$, the evaporative cooling was not significantly for wet and hybrid mode. For this zone, compared to the other four zones, the expander power and thermal efficiency of the ORC system with three cooling modes was higher than the other zone due to low ambient temperature variation throughout the year.

Effect of RH and ambient temperature on ORC performance -Leh (Cold and sunny conditions)

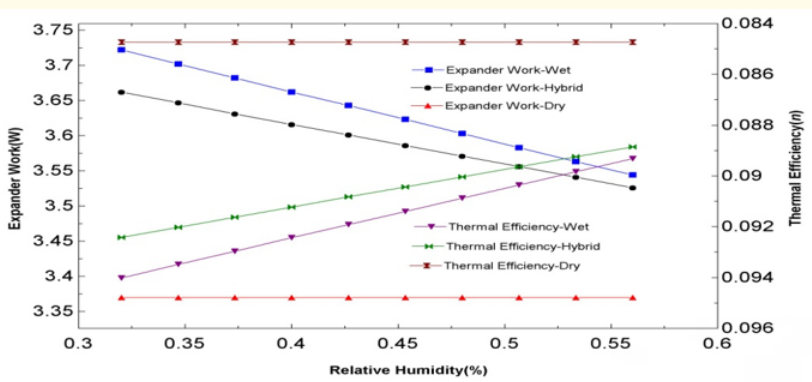

Figure 17: Influence of RH on expander work and thermal efficiency.

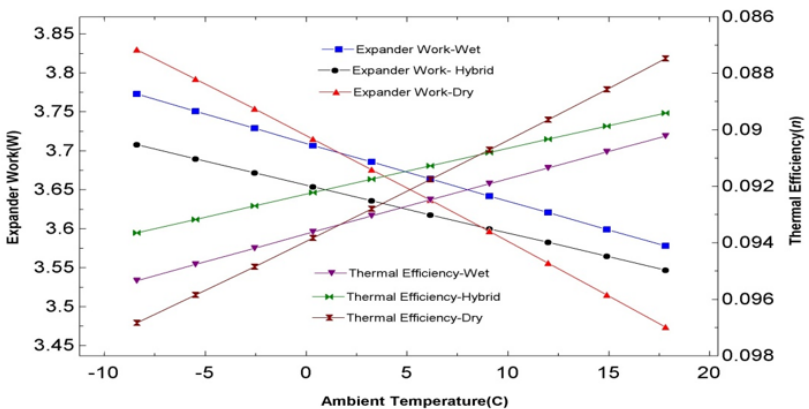

Figure 18: Effect of ambient temperature on expander power and thermal efficiency.

Figure 17 and figure 18 show the effect of monthly averaged $\mathrm{RH}$ and ambient temperature on ORC power output and thermal efficiency with wet, hybrid, and dry mode of cooling. The range of 
RH and ambient temperature for this zone was $32 \%$ (June) to $56 \%$ (January) and - 8.4 (January) to 17.4 (July). The expander power decreases from $3.722 \mathrm{~kW}$ to $3.544 \mathrm{~kW}(4.872 \%)$ with wet mode and $3.662 \mathrm{~kW}$ to $3.526 \mathrm{~kW}(3.713 \%)$ with hybrid mode when the relative humidity varies from $32 \%$ to $56 \%$ with ambient temperature 17.4. With the dry mode, the expander power output and thermal efficiency was $3.37 \mathrm{~kW}$ and $8.473 \%$. The thermal efficiency of ORC decreases from $9.401 \%$ to $8.931 \%$ (4.99\%) and $9.242 \%$ to $8.885 \%$ $(3.862 \%)$ with wet and hybrid mode, respectively. The output of ORC reduces from $3.773 \mathrm{Kw}$ to $3.578 \mathrm{~kW}$ (5.168\%) and $3.708 \mathrm{~kW}$ to $3.547 \mathrm{~kW}$ (4.314\%) with wet and hybrid mode when the ambient temperature varies from - 8.4 to 17.4 at fixed RH of $40 \%$. Expander power reduces from the $3.83 \mathrm{~kW}$ to $3.474 \mathrm{~kW}$ (9.295\%) with dry mode. ORC thermal efficiency decreases from $9.683 \%$ to $8.747 \%$ (9.66\%) with dry cooling mode. Also, it reduces from $9.534 \%$ to $9.022 \%(5.370 \%)$ and $9.364 \%$ to $8.94 \%$ (4.527\%) for wet and hybrid cooling mode. The result shows that ORC power output and thermal efficiency for dry cooling mode was better when the ambient temperature is below 1 . At the low temperature, the effect of $\mathrm{RH}$ was not significant. These findings can be compared with the results of ref [13]. As compared to the other five zones, the expander power and efficiency of ORC was relatively high because of moderate relative humidity and low ambient temperature throughout the year.

\section{Conclusion}

This paper presents the thermodynamic analysis of the Organic Rankine Cycle (ORC) system with a dry, wet, and dry/wet cooling tower for six climatic zones of India. The source temperature was fixed at 100 . The sink conditions vary for different climatic conditions. The effect of monthly averaged relative humidity and ambient conditions on ORC system performance was studied. The result shows that the increase in relative humidity and ambient temperature leads to a decrement of expander power output and thermal efficiency of ORC. The following points summarized as:

- $\quad$ The ORC performance was observed maximum in the cold and sunny zone (Leh). For the RH variation from $32 \%$ to $56 \%$ at 17.4 ambient temperature, the maximum expander power output and efficiency were $3.722 \mathrm{~kW}$ and $9.40 \%$. Also, with ambient temperature variation of -8.4to 17.4 at fixed $40 \%$ RH the maximum expander power output and efficiency was $3.83 \mathrm{~kW}$ and $9.683 \%$ with dry mode. At the ambient temperature below, 1 ORC performs better as at low-temperature effect of RH was not significant.
- The minimum performance of ORC was in the hot and dry zone (Jodhpur). For ambient temperature variation from 17.45to 34.52 at fixed $60 \% \mathrm{RH}$, the maximum expander power and efficiency were $2.775 \mathrm{~kW}$ and $6.909 \%$ with wet mode, respectively. Also, with $\mathrm{RH}$ variation from $30 \%$ to $69 \%$, and the fixed temperature 34.52 , the maximum power and efficiency was $2.805 \mathrm{~kW}$ and $6.98 \%$. The ORC performance with the hybrid cooling tower was in between dry and wet. As the weather is dry in this zone, and the amount of water is low in this zone. So the dry cooling tower is preferred for this zone although the performance is low. The hybrid cooling tower has the potential to reduce water consumption. So for the better ORC performance with hybrid cooling could be implemented for this zone with maximum cooling load shared with the dry section.

- In the composite zone (Varanasi), the Organic Rankine Cycle (ORC) system performance varies drastically because of a large variation in relative humidity and ambient temperature throughout the year. The ORC performance with hybrid cooling mode was in between the wet and dry mode. So for the city like Varanasi, the hybrid cooling tower could be beneficial as the large climatic variation, and also this arrangement saves consumption of the amount of water.

In the present study a numerical study was conducted to examine the performance of ORC. In the future design and experimental study will perform of hybrid cooling tower with ORC system. Also, proper load allocation for dry and wet section and water saving analysis for hybrid cooling towers will be evaluated to under different zone.

\section{Acknowledgement}

The authors would like to acknowledgement the Council of Science and Technology, Uttar Pradesh, Lucknow, India for their financial support.

\section{Bibliography}

1. JF Wang., et al. "Thermodynamic analysis and optimization of an ORC (organic Rankine cycle) using low-grade heat source". Energy 49 (2013): 356-365.

2. S Quoilin., et al. "Study of an organic Rankine cycle associated to a biomass-fuelled boiler for cogeneration application". Applied Energy 40 (2006): 2015-2023. 
3. S Clemente., et al. "Energy efficiency analysis of organic Rankine cycles with scroll expanders for cogenerative applications". Applied Energy 97 (2012): 792-801.

4. JF Wang., et al. "Parametric analysis, and optimization of a building cooling heating power system driven by solar energy based on organic working fluid". International Journal of Energy Research 37.12 (2013): 1465-1474.

5. Declaye S., et al. "Experimental study on an open drive scroll expander integrated into an ORC (organic Rankine cycle) system with R245fa as working fluid". Energy 55 (2013): 173-183.

6. Yang H., et al. "Coupling effect of evaporation and condensation processes of organic Rankine cycle for geothermal power generation improvement". Journal of Central South University 26 (2019): 3372-3387.

7. Zhang J., et al. "Improvement Research of Condensing Equipment in Organic Rankine Cycle Power Generation Systems, Proceedings World Geothermal Congress 2020". Reykjavik, Iceland (2020).

8. Bianchi M., et al. "Experimental analysis of a micro-ORC driven by piston expander for lowgrade heat recovery". Applied Thermal Engineering 148 (2019): 1278-1291.

9. Pili R., et al. "Effect of cold source conditions on the design and control of organic rankine cycles for waste heat recovery from industrial processes". Proceedings of ecos 2019-the $32^{\text {nd }}$ international conference on efficiency, cost, optimization, simulation, and environmental impact of energy systems wroclaw, Poland (2019): 23-28.

10. E Galloni., et al. "Design and experimental analysis of a miniORC (organic Rankine cycle) power plant based on R245fa working fluid". Energy 90 (2015): 768-775.

11. Liu Q., et al. "Performance analyses of geothermal organic Rankine cycles with selected hydrocarbon working fluids". Energy 63 (2013): 123-132.

12. Walraven D., et al. "Economic system optimization of aircooled organic Rankine cycles powered by low-temperature geothermal heat sources". Energy 80 (2015): 104-113.

13. Ghasemi H., et al. "Modeling and optimization of a binary geothermal power plant". Energy 50 (2013): 412-428.

14. Walraven D., et al. "Minimizing the levelized cost of electricity production from low-temperature geothermal heat sources with ORCs: water or air cooled?" Applied Energy 142 (2015): 144-153.
15. Korolija I and Greenough R. "Modelling of the influence of climate on the performance of the 612 organic Rankine cycle for industrial waste heat recovery". Energies 9.335 (2016): 1-20.

16. Muhammad Usman., et al. "Thermo-economic comparison of air-cooled and cooling tower based Organic Rankine Cycle (ORC) with R245fa and R1233zde as candidate working fluids for different geographical climate conditions". Energy 123 (2017): 353-366.

17. Zheng Miao., et al. "Experimental and modeling investigation of an organic Rankine cycle system based on the scroll expander". Energy 134.1 (2017): 35-49.

18. Jahar Sarkar and Souvik Bhattacharyya. "Potential of organic Rankine cycle technology in India: Working fluid selection and feasibility study". Energy 90 (2015): 1618-1625.

19. Imran M., et al. "Comparative assessment of Organic Rankine Cycle integration for low temperature geothermal heat source applications". Energy 102 (2016): 473-490.

20. Tian Hua., et al. "Fluids and parameter optimization for the organic Rankine cycles (ORCs) used in exhaust heat recovery of the Internal combustion engine (ICE)". Energy 47 (2012):125136.

21. AVL Powertrain Engineering. A quantum leap for heavy-duty truck engine efficiency-hybrid power system of diesel and WHR-ORC engines. The 12th Diesel Engine-Efficiency and Emissions Research Conference.

22. Gequn Shu., et al. "Experimental comparison of R123 and $\mathrm{R} 245 \mathrm{fa}$ as working fluids for waste heat recovery from heavyduty diesel engine". Energy 115 (2016): 756-769.

23. Shih-Cheng Yang., et al. "Experimental investigation on a 3-kW organic Rankine cycle for low grade waste heat under different operation parameters". Applied Thermal Engineering 113 (2017): 756-764.

24. Bansal N K and Minke G. "Climatic Zones and Rural Housing in India”. (Scientific series of the International Bureau/Forschugszentrum Julich GmbH) 35 (1988).

25. Tyagi A P. "Solar radiant energy over India, India meteorological department”. Ministry of earth sciences, New Delhi (2009).

26. M Kuansathan. "Performance Evaluation of Hybrid (Wet/Dry) Cooling Tower in Thailand (Master Thesis of Mechanical Engineering)". King Mongkut's University of Technology Thonburi, Bangkok, Thailand (2014). 
27. Hasan A and Siren K. "Performance investigation of plain circular and oval tube evaporatively cooled heat exchangers". Applied Thermal Engineering 24.5-6 (2014): 777-790.

28. O PR and E TR. "The heat and mass transfer characteristics of evaporative coolers". Chemical Engineering Progress Symposium 57.32 (1961): 138-149.

29. T M., et al. "Experimental study of an evaporative cooler". International Chemical 618 Engineering 7.4 (1967): 727-732.

30. A Streng. "Combined wet/dry cooling towers of cell type construction”. Energy Engineering 124 (1998): 104-121.

31. Asvapoositkul W and Kuansathan M. "Comparative evaluation of hybrid (dry/wet) cooling tower performance". Applied Thermal Engineering 71 (2014): 83-93.

32. Hall S. 6 - Fans, Blowers, and Compressors. Branan's. "Rules of Thumb for Chemical Engineers" (Fifth Edition). Oxford: Butterworth-Heinemann (2012): 118-133.

Volume 5 Issue 12 December 2021

(c) All rights are reserved by Saurabh Pathak and SK

Shukla.

Citation: Saurabh Pathak and SK Shukla. "Thermodynamic Analysis of Small Scale Organic Rankine Cycle (ORC) System Based on Dry, Wet and Dry/Wet (Hybrid) Cooling Towers Under Six Climatic Zones of India". Acta Scientific Agriculture 5.12 (2021): 17-30. 